\title{
Low cost, highly sensitive and selective electrochemical detection of arsenic (III) using silane grafted based nanocomposite
}

\author{
Jongte Lalmalsawmi ${ }^{1}$, Zirlianngura ${ }^{1}$, Diwakar Tiwari ${ }^{{ }^{\dagger}}$, Seung-Mok Lee $^{2^{\dagger}}$ \\ ${ }^{1}$ Department of Chemistry, School of Physical Science, Mizoram University, Aizawl-796004, India \\ ${ }^{2}$ Department of Environmental Engineering, Catholic Kwandong University, Gangneung 25601, Republic of Korea
}

\begin{abstract}
Novel silane grafted bentonite was obtained using the natural bentonite as precursor material. The material which is termed as nanocomposite was characterized by the Fourier Transform Infra-red (FT-IR) and X-ray diffraction (XRD) methods. The surface imaging and elemental mapping was performed using Scanning Electron Microscopic (SEM/EDX) technique. The electroanalytical studies were performed using the nanocomposite electrode. The electroactive surface area of nanocomposite electrode was significantly increased than the pristine bentonite or bare carbon paste based working electrode. The impedance spectroscopic studies were conducted to simulate the equivalent circuit and Nyquist plots were drawn for the carbon paste electrode and nanocomposite electrodes. A single step oxidation/reduction process occurred for As(III) having $\Delta \mathrm{E}$ value $0.36 \mathrm{~V}$ at $\mathrm{pH}$ 2.0. The anodic stripping voltammetry was performed for concentration dependence studies of As(III) $(0.5$ to $20.0 \mu \mathrm{g} / \mathrm{L})$ and reasonably a good linear relationship was obtained. The detection limit of the As(III) detection was calculated as $0.00360 \pm 0.00002 \mu \mathrm{g} / \mathrm{L}$ having with observed relative standard deviations (RSD) less than 4\%. The presence of several cations and anions has not affected the detection of As(III) however, the presence of Cu(II) and $\mathrm{Mn}(\mathrm{II})$ affected the detection of As(III). The selectivity of As(III) was achieved using the Tlawng river water sample spiked with As(III).
\end{abstract}

Keywords: As(III), Detection limit, Electrochemical sensor, Interfering ions, Nanocomposite, Tlawng river water

\section{Introduction}

The technological advancement greatly supported the healthcare sector. The devices developed for the efficient and selective detection of several medically important species is profoundly witnessed in improved quality of human life globally [1-3]. In a line the miniaturization of low-cost and robust detection devices are in greater demand for various healthcare units [4-5]. Further, variety of contaminants that enters into the biosystem through the aquatic environment is a serious concern for the developed or the developing nations. A suitable detection system could help in proper remediation of these contaminants from aquatic environment.

Arsenic is ubiquitous, naturally occurring, heavy metal and it is widely distributed in soil, sediment, water, aerosol, rain, aquatics and vegetations [6]. Arsenic is highly toxic and found carcinogenic and showed serious endanger to the human being exposed to it. Arsenic enters into the human body by two different possible pathways viz., by drinking arsenic contaminated water or by the consumption of plants that are cultivated in the arsenic contaminated soils [7]. It was reported previously that arsenic was detected in ground water in many countries around the globe and more than 200 million people are directly or indirectly exposed to it [8]. The hyperkeratosis on the palm or feet, bladder cancer and mutagenic effects is often occurs with arsenic consumption in humans [9-10] Therefore, because of its acute toxicity, the U.S. Environmental Protection Agency (EPA) and World Health Organization (WHO) has recommended the maximum contaminant level (MCL) of arsenic is $10 \mathrm{ppb}(130 \mathrm{nM})$ in drinking water [11-12]. Therefore, this compels to introduce newer analytical techniques having adequate reliability, extremely low detection limit and importantly robust in on-site detection of arsenic. This eventually, helps in safeguarding the human population living around this contaminated area and bound to consume the arsenic contaminated ground/fresh water. Several analytical methods were proposed in literature for the detection of low level of arsenic [12]. The surface plasmon resonance materials are found useful in the low level colorimetric detection of arsenic [13-15]. In this regard, the electrochemical methods are found prominent in the arsenic detection because of its reliability,
This is an Open Access article distributed under the terms of the Creative Commons Attribution Non-Commercial License (http://creativecommons.org/licenses/by-nc/3.0/) which permits unrestricted non-commercial use, distribution, and reproduction in any medium, provided the original work is properly cited.
Received June 12, 2019 Accepted August 12, 2019

${ }^{\dagger}$ Corresponding author

Email: diw_tiwari@yahoo.com, leesm@cku.ac.kr Tel: +91-9862323015, +82-33-649-7535

Copyright (C) 2020 Korean Society of Environmental Engineers 
low cost, easy handling and importantly the on-site use [16, 17]. Fluorine doped cadmium oxide thin film sensor was introduced. The sensor showed a detection limit and efficiency for arsenic is $4.55 \times 10^{-3} \mathrm{ppb}$ and $5.747 \times 10^{-3} \mathrm{~mA} / \mathrm{ppb}$ [18]. Role of advanced materials is impetus in fabrication of arsenic sensor. In a line, L-leucine modified graphene oxide (GO) was coated onto the gold electrode and utilized in the detection of arsenic(III). The results indicated that the sensitivity and detection limit of electrode was found to be excellent $\sim 30 \mathrm{~mA} / \mathrm{ppm} / \mathrm{cm}^{2}$ and of $0.5 \mathrm{ppm}$, respectively [1]. An electric discharge process at $1.2 \mathrm{kV}$ was utilized to obtain the gold (NPs) followed by $\mathrm{Au}(\mathrm{NPs})$ and eutectic $\mathrm{Au} / \mathrm{Si}$ alloy were (AuNPs) used for the graphite screen printed electrode [5]. The electrode was introduced in the arsenic detection showing the detection limit of $0.22 \mathrm{ppb}$ however, a pre ion exchange resin is required in presence of copper. The linear sweep voltammetry was utilized in the low detection of As(III) using the graphite pencil electrode modified with tin oxide nanoneedles. The electrochemical system enabled to provide a detection limit $10 \mathrm{ppb}$ at measured sensitivity of $28.13 \mu \mathrm{A} / \mathrm{cm}^{2} / \mathrm{ppb}$ [19]. Electrochemically etched gold wire microelectrode (Au-ME) was utilized in the low level detection of arsenic(III), arsenic (V) and total inorganic arsenic using the anodic stripping voltammetry. The impedance data revealed that a simple electrochemical reaction was taken place at Au-ME electrode having the electrode resistance of $\mathrm{R}_{\mathrm{e}}=1.8 \mathrm{~kW}$ [21]. Bismuth modified exfoliated graphite electrode was introduced in the square wave anodic stripping voltammetry. The detection of As(III) was conducted at pH 6.0 and showed a LOD $5 \mathrm{mg} / \mathrm{L}$. Further, the detection was affected with several interfering ions other than $\mathrm{Cu}$ (II) [20]. Hydrothermally $\mathrm{Au}-\mathrm{Cu}$ bimetallic nanoparticles were obtained and utilized for the ultra-trace detection of arsenic(III) using the square wave anodic stripping voltammetry (SWASV). The detection of arsenic was almost unaffected in presence of several cations and the detection sensitivity and LOD was found to be $1.63 \mathrm{~mA} / \mathrm{ppb} / \mathrm{cm}^{-2}$ and $2.09 \mathrm{ppb}$, respectively [21]. These studies indicated that the use of advanced materials play an important role in the development of arsenic sensor for ultra-low level detection. The low cost materials with adequate efficiency and selectivity is useful in the advancement of sensor studies.

Therefore, novel nanocomposite precursor to natural bentonite is synthesized and it was first time utilized in the modification of carbon paste electrode. The electrochemical and impedance spectroscopy was studied and the nanocomposite electrode was further utilized in the ultra-trace detection of arsenic(III). The real matrix water sample was used in the efficient arsenic detection.

\section{Experimental Section}

\subsection{Materials}

The bentonite powder and sodium meta arsenite was obtained from the HiMedia Chemicals, India. Trichloro(octadecyl)silane, carbon (glassy spherical powder 2 12 mm) were obtained from the Sigma Aldrich, USA. Potassium chloride, potassium hexacyanoferrate(II) trihydrate, cadmium nitrate tetrahydrate and disodium hydrogen phosphate anhydrous were obtained from the Merck India. Ethylene diamine tetra-acetic acid was obtained from Qualigens Fine Chemicals, India and Manganese chloride was pro- cured from SD Fine Chemicals Ltd. India. The purified water was obtained from the water purification System (Sartorius, Model-Arium Mini Plus UV Lab. Water System). All the chemicals were of Analytical grade and were utilized without further purification.

Electrochemical workstation (Potentiostat/Galvanostat; BioLogic Science Instruments, France, Model: SP 200) was employed to carry out the entire electrochemical/sensor studies. The electrochemical data was analyzed using in built computer software ECLabß. The Ag $\mid \mathrm{AgCl}$ was used as reference and platinum electrode was employed as auxiliary electrode in the three-electrode assembly. The working electrode was fabricated using the carbon powder and hybrid materials. X-ray diffraction (XRD) data was obtained by X-ray diffraction machine (PANalytical, Netherland; Model X'Pert PRO MPD). The data was recorded at the scan rate of 0.032 of $2 \theta$ illumination having the $\mathrm{CuK \alpha} \alpha_{1}$ and $\mathrm{CuKa} \alpha_{2}$ radiations having wavelengths 1.5406 and $1.54443 \AA$. The FT-IR (Fourier Transform- Infra red), Shimadzu, Japan (model: IRAffinity-1S WL) was used to obtain the FT-IR data of solids. Atomic absorption Spectrometer (AAS) Shimadzu AAS, Japan (Model: AA-7000 Series) was used. Weighing balance Wensar, India (Model HPB220) was employed. Similarly, the Labtronics Microprocessor $\mathrm{pH}$ meter, India (Model LT-50) was used for $\mathrm{pH}$ measurements. The multiparameter of water was obtained using the Hanna Instrument, USA (Model: HI98194). The TOC (total organic carbon) value of water obtained by the TOC analyzer, Shimadzu, Japan (Model: TOC-VCPH/CPN).

\subsection{Methodology}

Bentonite was grafted with trichloro(octadecyl)silane (TCODS). The bentonite was washed with distilled water and dried in drying oven at $105^{\circ} \mathrm{C}$ for $24 \mathrm{~h}$. The dry and cooled bentonite (12 g) was dispersed in $300 \mathrm{~mL}$ of toluene and the suspension was stirred for 30 min under the $\mathrm{N}_{2}$ atmosphere. Further, under the stirred condition of this suspension, trichloro(octadecyl)silane (12 mL) was added slowly. The suspension mixture was refluxed at $80^{\circ} \mathrm{C}$ for $24 \mathrm{~h}$ under the $\mathrm{N}_{2}$ atmosphere. The solid was filtered using a Whatman filter paper and it was gently washed with toluene followed by ethanol. The TCODS grafted bentonite was dried in drying oven at $60^{\circ} \mathrm{C}$ for $24 \mathrm{~h}$. It was then stored in air tight polyethylene bottle. The grafted bentonite (nanocomposite) was characterized by FE-SEM, FT-IR and XRD analyses.

The working electrode was fabricated using the carbon powder and the nanocomposite or pristine bentonite powder. The carbon powder and bentonite/hybrid material were taken in the ratio of $6: 1(w / w)$. Further, the powder of these two was mixed thoroughly and paste was prepared adding $1 \mathrm{~g}$ of paraffin oil. The paste was manually introduced to pack a Teflon tube $(5 \mathrm{~cm}$ in length and radius of $0.21 \mathrm{~cm}$ ). The top of the tube is sealed with Teflon tape and then gently a titanium wire was inserted inside the tube to ensure proper electrical connectivity. The bottom end of the tube was kept open which was ready to use as working electrode. Further, at the completion of each cyclic voltammetry experiments, the open surface of tube was washed with distilled water, polished with glassy paper and again was used.

The electrochemical cell contained with the three electrodes 
viz., Ag $\mid \mathrm{AgCl}$ (satd.) reference electrode, Pt as auxiliary electrode and fabricated working electrode was used for electrochemical studies. The cell is closed and $\mathrm{N}_{2}$ was bubbled throughout collecting the electrochemical data.

\subsection{Electrochemical Impedance Spectroscopic Analysis}

The electrochemical impedance spectroscopic data was collected using the cyclic voltammeter employing the $1.0 \mathrm{mmol}$ of ferrous/ferric cyanide solution having the background electrolyte concentration $0.1 \mathrm{KCl}$. The frequency range was used $80 \mathrm{kHz}$ to $100 \mathrm{mHz}$ with 6 points per decade at an employed $10 \mathrm{mV}$ peak to peak sinusoidal potential. Further, in order to study the characteristics of electrode in the mass transfer reactions, the scan rate studies were conducted using $1.0 \mathrm{mmol}$ of ferrous/ferric cyanide solution having the background electrolyte concentration $0.1 \mathrm{KCl}$ varying the scan rate from the $50 \mathrm{mV} / \mathrm{s}$ to $200 \mathrm{mV} / \mathrm{s}$.

A known concentration of arsenic(III) solution was prepared using the $0.1 \mathrm{~mol} / \mathrm{L} \mathrm{KCl}$ solution. The $\mathrm{KCl}$ solution $\mathrm{pH}$ was adjusted using the $0.1 \mathrm{~mol} / \mathrm{L} \mathrm{HNO}_{3}$ or $\mathrm{NaOH}$ solution. The cyclic voltammetric (CV) data was recorded at an exciting potential of $+1.0 \mathrm{~V}$ and -0.2 V against an $\mathrm{Ag} \mid \mathrm{AgCl}$ (satd.) reference electrode. The CV data was recorded for three consecutive cycles and the third cycle was utilized for further calculations. Moreover, six replicates were studied and hence the error was calculated and shown as $\pm 3 \sigma$ values. Further, anodic stripping voltammetry was employed for different electrochemical studies.

\subsection{River Water Analysis}

Water sample was collected from the Tlawng River, Aizawl (India). The multiparameter (conductivity, resistivity, salinity and oxidation reduction potential) of water quality was measured using multiparameter instrument. These parameters were obtained immediate after collecting the sample. The river water was analyzed for various elements using the AAS. Further, the NPOC (Non-purgeable Organic Carbon) of the river water was analyzed. The $0.1 \mathrm{~mol} / \mathrm{L} \mathrm{KCl}$ solution was prepared using the collected river water whose $\mathrm{pH}$ was previously adjusted. Further, this solution was spiked with the arsenic (III) to obtain the arsenic (III) concentrations 0.5 to $20.0 \mathrm{mg} / \mathrm{L}$. The solutions were subjected for the anodic stripping electrochemical analysis and calibration line was obtained between the concentration of arsenic (III) and anodic peak current.

\section{Results and Discussion}

\subsection{Characterization of Materials}

The SEM images of the bentonite and TCODS grafted bentonite (nanocomposite) is shown in Fig. 1. It is evident from the image that pristine bentonite possesses heterogeneous structure and silica content is visible on the surface of bentonite. Moreover, the layers of bentonite are orderly arranged on the surface. The porosity is evident by the pristine bentonite. On the other hand, the nanocomposite showed disordered structure and an enhanced heterogeneity was obtained on the surface of solid. It is evident that the silane molecules are occupying the places on the surface and likely to be grafted on the surface. The material is more compact and less porosity is visible. Similar results were reported previously when the 3-aminotriethoxysilane (APTES) was grafted with bentonite nano-clay and showed that the APTES is successfully grafted with bentonite [22].

Further, the EDX elemental mapping was conducted and EDX data is shown in Fig. 1 (Inset). The EDX mapping showed characteristic peaks of the $\mathrm{Si}, \mathrm{O}, \mathrm{Fe}, \mathrm{Mg}, \mathrm{Na}, \mathrm{C}$ etc. A similar mapping was obtained for the nanocomposite. However, an additional but prominent peak of $\mathrm{Cl}$ is visible in the grafted clay. This indicated that the TCODS molecule was successfully grafted with the bentonite network.

An x-ray diffraction spectrum of bentonite and nanocomposite is illustrated in Fig. 2(a). The figure showed that a good crystalline structure of bentonite is obtained in both the samples. The peak of (001) plane of pristine bentonite and nanocomposite occurred at the $2 \theta$ value of 5.89 and 5.65, respectively. Hence, the basal spacings $\mathrm{d}_{001}$ were obtained as 1.499 and $1.563 \mathrm{~nm}$, respectively for the pristine bentonite and nanocomposite. It is evident from these values that the basal spacing of nanocomposite is not significantly enhanced compared to the pristine bentonite. This indicates that TCODS molecules are not entered into the galleries of bentonite rather forming the bond with the broken edges of bentonite [23].

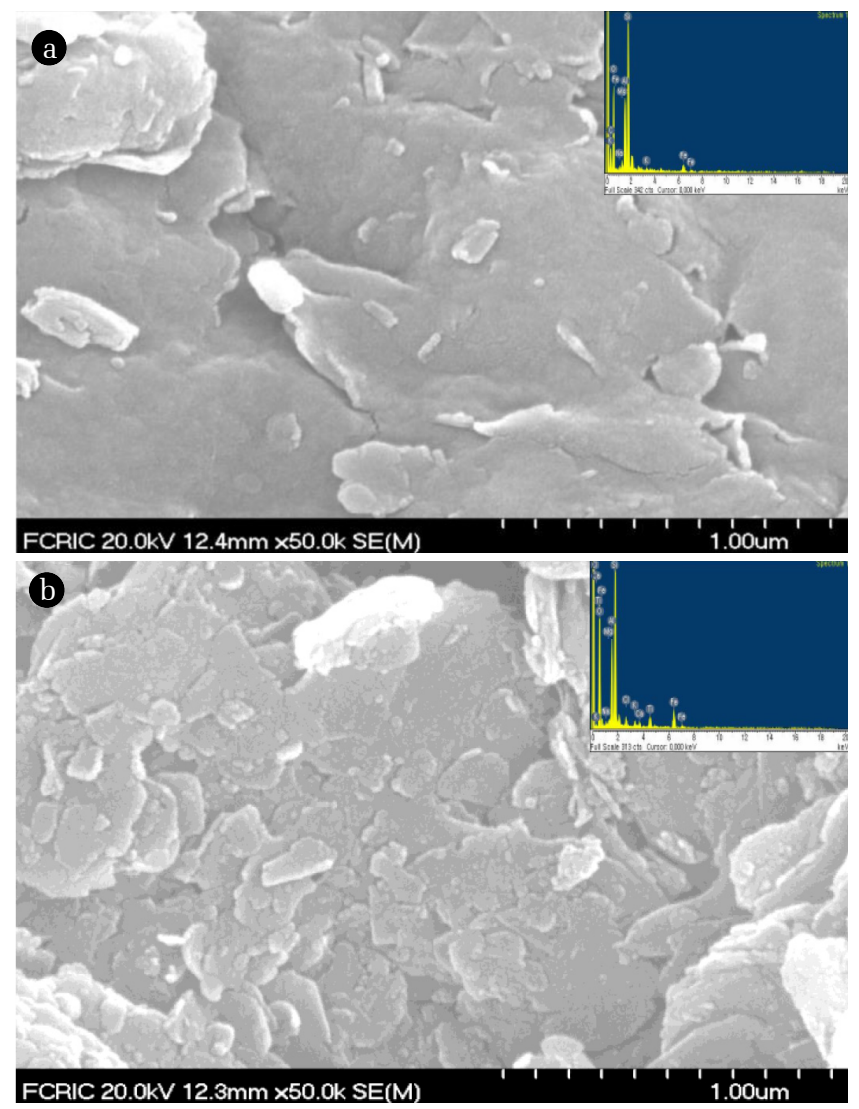

Fig. 1. SEM images of (a) Pristine bentonite and (b) Nanocomposite (Inset: SEM-EDX spectra of (a) Pristine bentonite and (b) Nanocomposite). 


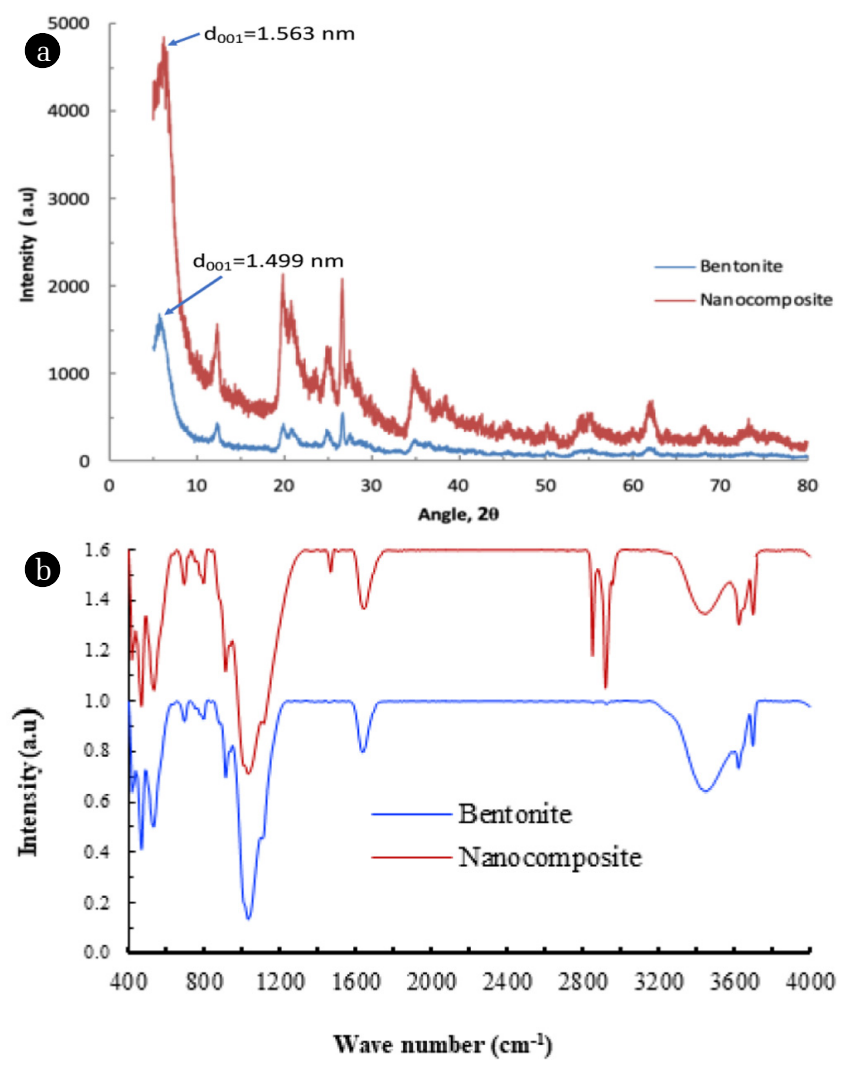

Fig. 2. (a) X-ray diffraction spectra and (b) FT-IR spectra of pristine bentonite and nanocomposite materials.

The FT-IR spectra of pristine bentonite and nanocomposite are shown in Fig. 2(b). Figure indicated that both the samples possessed with broad peaks around 3,440 and $1,643 \mathrm{~cm}^{-1}$ wave numbers. These are due to the stretching and bending vibrations of $-\mathrm{OH}$ groups of bentonitic water molecules [23]. Further, a band around the region $1,190-940 \mathrm{~cm}^{-1}$ is primarily due to the vibrations of $\mathrm{Si}-\mathrm{O}-\mathrm{Si}$ or Si-O-Al [24]. Further, bentonite showed vibration bands around 1,105, 1,020 and $696 \mathrm{~cm}^{-1}$ are due to $\mathrm{Si}-\mathrm{O}$ stretching vibrations. Moreover, $\mathrm{Al}-\mathrm{Al}-\mathrm{OH}$ hydroxyl-bending vibration is visible around $914 \mathrm{~cm}^{-1}$ [25]. Further, it is interesting to observe that the nanocomposite material showed two intense and sharp vibration peaks around the wave numbers 3039 and $2880 \mathrm{~cm}^{-1}$. This is due to the asymmetric and symmetric stretching of the $\mathrm{C}-\mathrm{CH}_{2}$ group of the alkyl chain. Additionally, the scissoring oscillations of aliphatic organic chain were prominently occurred around the wavenumber $1489 \mathrm{~cm}^{-1}$. Therefore, this confirms the grafting of the organic silane with the bentonite network.

\subsection{Electrochemical Impedance Spectroscopic Studies}

The electrochemical impedance spectroscopy of the electrodes with $\mathrm{Fe}(\mathrm{II}) / \mathrm{Fe}(\mathrm{III})$ standard solutions were conducted at $\mathrm{pH} 6.4$ using the background electrolyte $0.1 \mathrm{~mol} / \mathrm{L} \mathrm{KCl}$. This eventually demonstrates the solid (working electrode) -electrolytic solution interfacial behaviour. The applied frequency range was used $80 \mathrm{kHz}$ to 100 $\mathrm{MHz}$ with 6 points per decade at an employed $10 \mathrm{mV}$ peak to peak sinusoidal potential. The measured imaginary impedance $(\mathrm{Z} \phi)$ is plotted against the real impedance (Z). The results are shown in Nyquist plot (Fig. 3). Further, the equivalent circuits were drawn. The measured data was best fitted with the Randles circuit shown in Fig. 3 (Inset). The Randles circuit assumes the diffusional element (Warburg or Warburg short) which is connected in series with the charge transfer resistance [26]. Therefore, the equivalent circuit contained with the $R_{s}$ i.e., a series resistance comes due to solution, wires or even contact resistances, $C_{d}$ which is double layer capacitance at surface of electrode and electrolyte interface. The $R_{c t}$ is practically a charge transfer resistance which takes place at the electrode surface and bulk ionic species and $\mathrm{W}$ is the Warburg coefficient or Warburg diffusion impedance obtained because of diffusion of ionic species into the bulk solution [27]. The data is fairly fitted well to the Randles plot and the fitted values for bare carbon paste electrode and nanocomposite modified electrode are shown in Table S1. It is evident from the table S1 that the value of $R_{s}$ which is primarily solution resistance was almost identical in both the working electrodes employed. Semicircle diameter of Nyquist plot determines the interfacial charge transfer resistance [28]. It is noted that the semicircle diameter is significantly decreased using the nanocomposite electrode which enabled to an efficient and faster redox reactions at the interface [29].

Further, electrochemical performance of the working electrodes viz., carbon paste, bentonite and nanocomposite were utilized in the redox reactions using the $1.0 \mathrm{mmol} / \mathrm{L} \mathrm{Fe}(\mathrm{CN})_{6}{ }^{3+} / \mathrm{Fe}(\mathrm{CN})_{6}{ }^{4-}$ redox probe under the cyclic voltammetry. The excitation of potential was increased from the $50 \mathrm{mV} / \mathrm{s}$ to $200 \mathrm{mV} / \mathrm{s}$ and the potential window was used -0.5 to $1.0 \mathrm{~V}$. The results are presented graphically in Fig. S2. The hybrid materials modified carbon paste electrodes are then electrochemically characterized using the CV studies employing the $1.0 \mathrm{mmol} / \mathrm{L} \mathrm{Fe}(\mathrm{CN})_{6}{ }^{3+} / \mathrm{Fe}(\mathrm{CN})_{6}{ }^{4-}$ redox probe. The response with nanocomposite is significantly increased since the cathodic and anodic peak currents are significantly increased using the nanocomposite electrode. Therefore, the enhanced electrochemical signal received by using the nanocomposite inferred that nanocomposite material greatly facilitate the electron transfer reactions between the $\mathrm{Fe}^{2+} / \mathrm{Fe}^{3+}$ at the surface of electrode [30, 31]. The mass transfer reactions at electrode-electrolyte are studied using the Randle-Sevick equation [30,32]. The results are depicted in

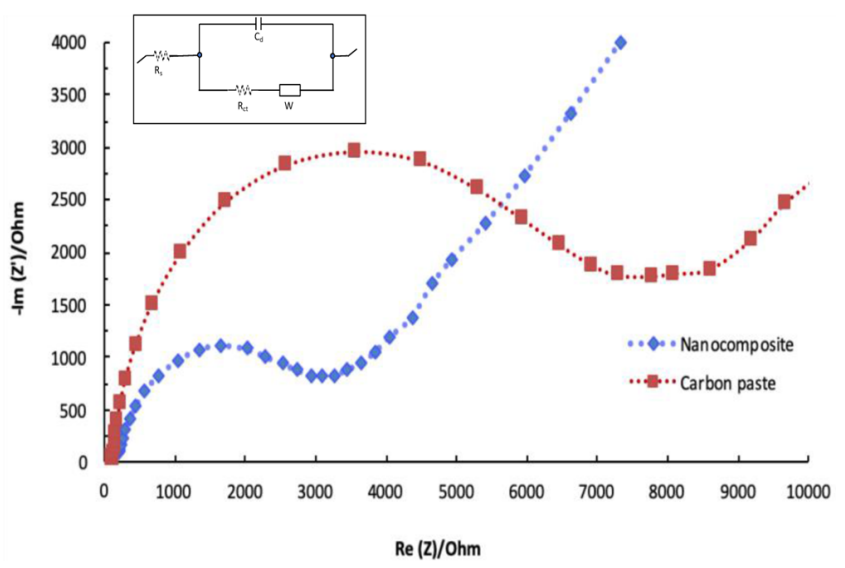

Fig. 3. Nyquist plots of carbon paste and nanocomposite materials. 
(Inset: Equivalent circuits of nanocomposite).

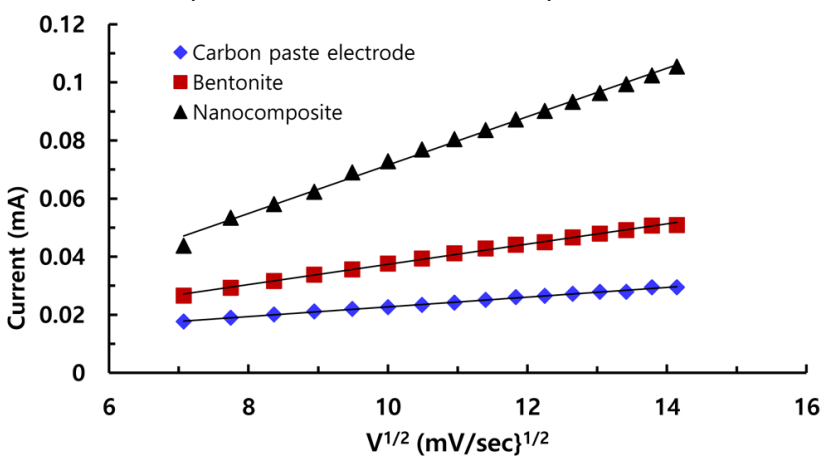

Fig. 4. Randle - Sevick plots for the carbon paste, pristine bentonite and nanocomposite electrodes.

Fig. 4. A linear relationship between the peak current and the square root of scan rate suggested clearly the interfacial kinetics is diffusion controlled [20]. Further, using the slope of these lines and the diffusion coefficient of $\mathrm{Fe}(\mathrm{CN})_{6}{ }^{3-} / \mathrm{Fe}(\mathrm{CN})_{6}{ }^{4-}\left(\mathrm{cm}^{2} / \mathrm{s}\right)$ in aqueous media $7.3 \times 10^{-6} \mathrm{~cm}^{2} / \mathrm{s}$, the electroactive surface area of these working electrodes were computed. The electroactive surface area of carbon paste, bentonite and nanocomposite electrodes are found to be $7.40 \times 10^{-3}, 1.52 \times 10^{-2}$ and $3.61 \times 10^{-2} \mathrm{~mm}^{2}$, respectively. It is interesting to note that the surface area of nanocomposite is 4.88 times higher than the carbon paste electrode and it is 2.37 times higher than the pristine bentonite electrode. This significant increase in electroactive surface area using nanocomposite electrode could enable to detect the arsenic (III) even at ultra-trace level. A similar diffusion controlled kinetics was suggested for the As(III) using the bismuth modified exfoliated graphite (EG-Bi)working electrode and reported that electroactive surface area was found to be $13.1 \mathrm{~mm}^{2}$ and $16.3 \mathrm{~mm}^{2}$, respectively for EG (exfoliated graphite) and EG-Bi electrode, respectively. [21].

\section{3. $\mathrm{pH}$ Dependence Electrochemical Studies of Arsenic (III)}

The cyclic voltammograms of arsenic (III) was obtained at various
$\mathrm{pH}$ values and shown in Fig. 5(a). It is evident from the figure that the arsenic possessed a characteristic anodic and cathodic peaks around the applied potential of 0.61 and 0.25 (vs $\mathrm{Ag} \mid \mathrm{AgCl}$ ), respectively (at $\mathrm{pH}$ 2.0). The arsenic concentration was chosen as $30.0 \mu \mathrm{g} / \mathrm{L}$. Moreover, the cathodic and anodic peaks are sharp and smooth. This infers that arsenic (III) undergoes with a single step 3 electron oxidation and reduction processes i.e., As(III) reduced to $\operatorname{As}(0)$ and $\operatorname{As}(0)$ oxidized to As(III). It was reported previously that the arsenic (III) was reduced in a single step process around applied potential of $-150 \mathrm{mV}$ and oxidized around $50 \mathrm{mV}$ using the bismuth modified exfoliated graphite (EG-Bi) working in a $0.1 \mathrm{M} \mathrm{KNO}_{3}(\mathrm{pH} \mathrm{6}$ ) [21]. The information obtained from the $\mathrm{CV}$ was used to determine the preconcentration potential. The observed $\Delta \mathrm{E}$ value is found to be $0.36 \mathrm{~V}$. Hence, the observed low value of $\Delta \mathrm{E}$ indicates that the redox process of arsenic is greatly favourable at the nanocomposite electrode [33]. The other studies showed that As(III) shows no redox reactions on to the CNTs (carbon nanotube) electrode however, gold-CNTs electrode showed a dominant cathodic peak at the potential $-0.25 \mathrm{~V}$ (vs SCE) and it was regarded 3 electron reduction of As(III) [34-35].

Further, the solution $\mathrm{pH}$ is an important parameter to be studied since the speciation of arsenite varies with $\mathrm{pH}$ [36]. As(III) exists predominantly within the $\mathrm{pH}$ region $2 \sim 8$ to its non-ionic form i.e., $\mathrm{H}_{3} \mathrm{AsO}_{3}$ which gradually turns to anionic species of $\mathrm{H}_{2} \mathrm{AsO}_{3}{ }^{-}$ beyond $\mathrm{pH}$ 8. On the other hand, the nanocomposite possessed the $\mathrm{pH}_{\mathrm{PZC}}$ value of 6.84 . Therefore, the nanocomposite carries net positive charge at $\mathrm{pH}<6.84$ and $\mathrm{pH}>6.84$ it possess net negative charge. The response of the $\mathrm{pH}$ dependence studies shown in Fig. 5(a); clearly shows that the electrochemical behaviour of arsenic(III) is almost similar at different $\mathrm{pH}$ values, however, the peak intensity and peak positions are greatly affected by varying the solution $\mathrm{pH}$. Increasing the $\mathrm{pH}$, the cathodic and anodic peak positions are greatly shifted with an enhanced $\Delta \mathrm{E}$ values. The increased $\Delta \mathrm{E}$ values make the redox process more non-favourable. However, at $\mathrm{pH} 2.0$ the $\Delta \mathrm{E}$ was found as low as $\mathrm{Ca} 0.34 \mathrm{~V}$ with significantly high current density. A similar observation was obtained for As(III) as the high current density was obtained at lower $\mathrm{pH}$ values using
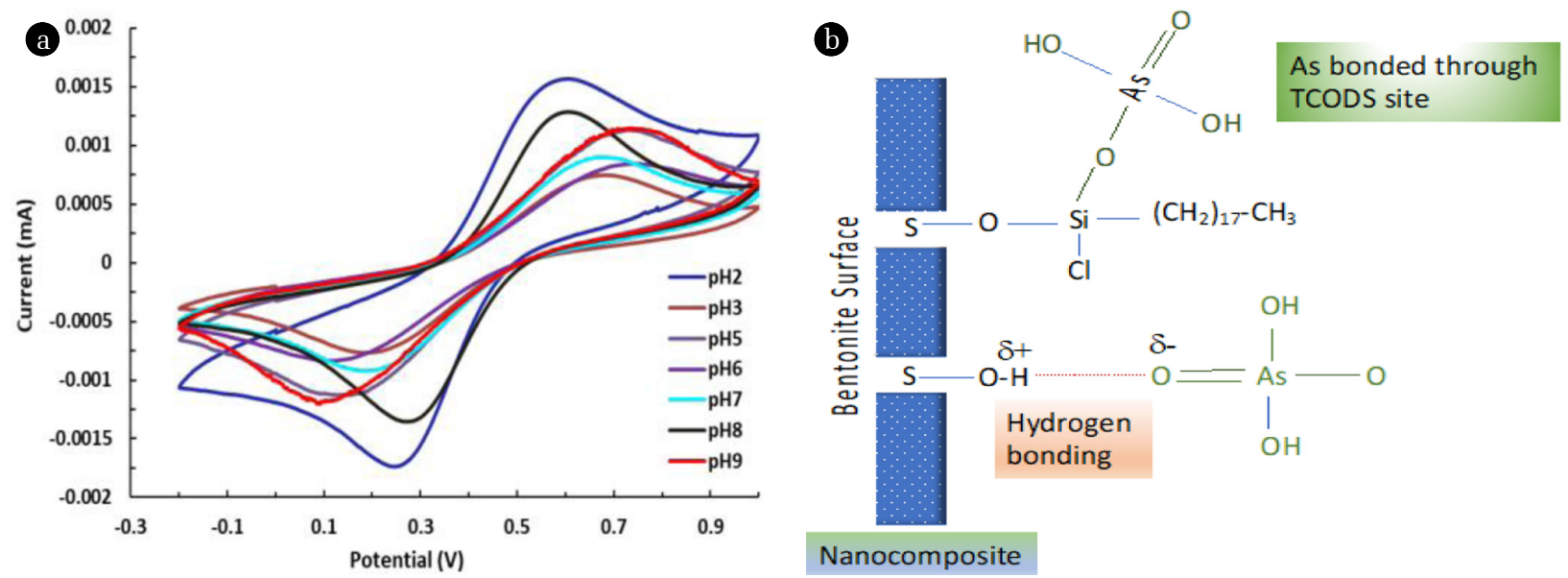

Fig. 5. (a) CV response of $\mathrm{As}$ (III) using the nanocomposite electrode as a function of $\mathrm{pH}$, and (b) Scheme of As(III) sorption onto the electrode surface. 
the EG-Bi electrode [21]. Low electrochemical signal received at higher $\mathrm{pH}$ conditions is possibly due to hydroxide formation that hinders the arsenic detection. Therefore, in view of the surface properties a possible mechanism of arsenic was proposed. It assumes that arsenic adsorbed on the surface of nanocomposite with relatively strong chemical bonds at the electrode surface and giving enhanced signal of cathodic or anodic peaks. The bonding sites are, possibly, having of two types as depicted in Eq. (1) and (2):

$$
=\mathrm{S}-\mathrm{O}-\mathrm{Si}-\left(\mathrm{CH}_{2}\right)_{17}-\mathrm{CH}_{3} \mathrm{Cl}_{2}+2 \mathrm{H}_{3} \mathrm{AsO}_{4} \rightarrow-\mathrm{S}-\mathrm{O}-\mathrm{Si}-\left(\mathrm{CH}_{2}\right)_{17}-\mathrm{CH}_{3}+2 \mathrm{HCl}
$$<smiles>OC(O)C(O)(O)[C@@H](O)O[Si]</smiles>

It is therefore evident that a chemical bonding is taken place between the nanocomposite arsenite molecules which undergoes redox reactions at the surface of solid [37]. The other possibility is due to the presence of unoccupied bentonite surface site. The surface is likely to form a strong hydrogen bond with the arsenite molecule (Eq. (2); Fig. 5(b)) [38]. Therefore, presence of arsenite on the electrode surface either by the chemical bonding or by the hydrogen bonding enabled efficiently the redox process to take place at the surface. Hence; an enhanced electrochemical signal was received.

\subsection{Anodic Stripping Voltammetry for Arsenic (III) Calibration}

The electrochemical response of arsenic(III) using the bare carbon paste, pristine bentonite and nanocomposite modified working electrodes is conducted having the As(III) concentration $50.0 \mu \mathrm{g} / \mathrm{L}$ at $\mathrm{pH} 2.0$ in $0.1 \mathrm{~mol} / \mathrm{L} \mathrm{KCl}$ solution. The results are illustrated in Fig. S3. It is evident from the figure that the cathodic and anodic peak currents are significantly increased using the nanocomposite modified carbon paste electrode. The bare carbon paste electrode or pristine bentonite modified carbon paste electrode showed, not only, much reduced electrochemical signal as well the cathodic and anodic peaks of As(III) oxidation/reduction are invariably disordered. The results clearly showed the significance and potential of nanocomposite in the low level detection of As(III) from aqueous solutions.

The As(III) detection was carried out using the anodic stripping voltammetry at the applied potential of 0.4 to $1.0 \mathrm{~V}$. The stripping voltammetry is a useful electrochemical tool since it provides precisely low detection limit [39]. Moreover, the selectivity and sensitivity of detection is enhanced using the stripping voltammetry. Therefore, the anodic stripping voltammetry curves were obtained varying the concentration of As(III) from $0.5 \mathrm{mg} / \mathrm{L}$ to $20.0 \mu \mathrm{g} / \mathrm{L}$ at $\mathrm{pH} 2.0 \mathrm{in} 0.1 \mathrm{~mol} / \mathrm{L} \mathrm{KCl}$ employing the nanocomposite electrode. The results are depicted in Fig. 6. It is evident from the figure that an increase in concentration of As(III) caused to increase the anodic peak current. Further, the calibration line was obtained between the anodic peak current and As(III) concentration. The results are shown in Fig. 6 (Inset). Figure showed that fairly a good linearity was obtained between the anodic peak current and As(III) concentration. Further, the linear regression of straight line was obtained and the obtained equation is $\mathrm{I}_{\mathrm{A}}(\mathrm{mA})=0.0276 \mathrm{x}$ $\mathrm{C}(\mu \mathrm{g} / \mathrm{L})+0.168\left(\mathrm{R}^{2}=0.979\right)$. The results indicated that the detection of arsenic is efficiently obtained even at very low concentration of arsenic in aqueous media. Limit of detection (LOD) and limit of quantification (LOQ) was further obtained using the known Eq. (3) and (4), where 's' is standard deviation of blank solution and ' $\mathrm{m}$ ' is the slope of the calibration line.

$$
\begin{gathered}
L O D=3 \times \frac{s}{m} \\
L O Q=10 \times \frac{s}{m}
\end{gathered}
$$

\begin{tabular}{|c|c|c|c|}
\hline Method employed & Materials used & LOD & Reference \\
\hline Electrochemical method (SWAS) & EG-Bi (Bi modified Exfoliated graphite) & $5.0 \mu \mathrm{g} / \mathrm{L}$ & {$[22]$} \\
\hline Glassy carbon electrode & Au modified & $0.022 \mu \mathrm{g} / \mathrm{L}$ & {$[42]$} \\
\hline Carbon paste electrode & Au Nanoparticles modified & $0.38 \mu \mathrm{g} / \mathrm{L}$ & [43] \\
\hline Florescence Resonance energy transfer & $\begin{array}{l}\text { Acriflavine (energy donor) and } \\
\text { Rhodamine B (energy acceptor) }\end{array}$ & $10.0 \mu \mathrm{g} / \mathrm{L}$ for $\mathrm{As}(\mathrm{V})$ & {$[40]$} \\
\hline Electrochemical & F-doped CdO electrode & $0.0045 \mu \mathrm{g} / \mathrm{L}$ & [19] \\
\hline Electrochemical & Ultra-thin graphene oxide film & $0.5 \mathrm{ppm}$ & {$[1]$} \\
\hline Electrochemical & AuNPs-EGE (Exfoliated graphite electrode) & $0.58 \mathrm{ppb}$ & [44] \\
\hline Plasmon resonance & Lauryl sulphate (LS) modified gold nanoparticles & $2.0 \mu \mathrm{g} / \mathrm{L}$ & {$[15]$} \\
\hline Electrochemical & $\mathrm{Au}$ electrode modified with DNA & $0.02 \mathrm{ppb}$ & {$[31]$} \\
\hline Electrochemical & Nanocomposite* & $0.00360 \pm 0.00002 \mu \mathrm{g} / \mathrm{L}$ & Present study \\
\hline
\end{tabular}

The LOD for six replicates was obtained to be $0.00360 \pm 0.00002$

Table 1. Comparison of Arsenic Detection using Different Materials and Different Methods

\footnotetext{
* Silane grafted bentonite
} 
$\mu \mathrm{g} / \mathrm{L}$. Similarly, the LOQ was calculated as $0.0120 \pm 0.0003 \mu \mathrm{g} / \mathrm{L}$.

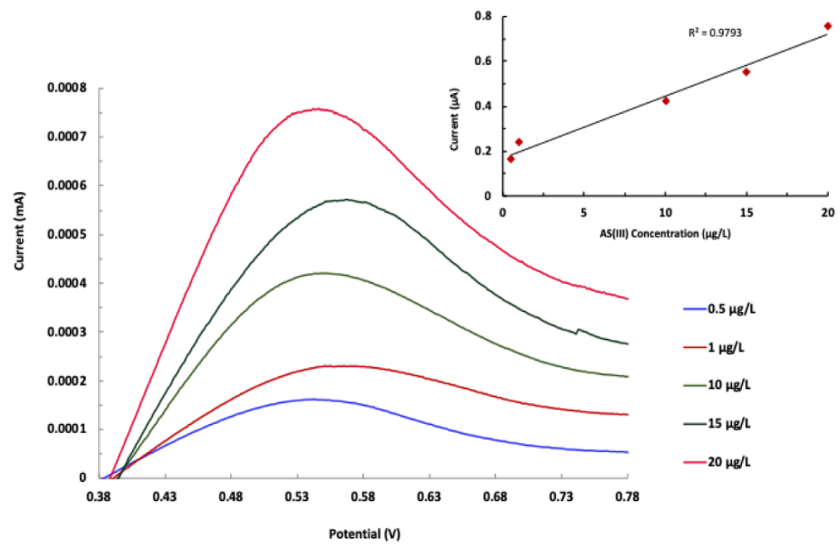

Fig. 6. Anodic stripping voltammetric curves for various concentration of As(III) (Inset: Calibration line for the detection). Potential vs. $\mathrm{Ag} / \mathrm{AgCl}(0.1 \mathrm{~mol} / \mathrm{LKCl}$ and $\mathrm{pH} 2.0)$.

The LOD is found to be much below to the EPA limit of arsenic in the fresh water that enables greater applicability of analytical method. Moreover, the replicates of data showed a good reproducibility of results as the observed relative standard deviations (RSD) was obtained always less than $4 \%$. The results obtained are compared with the other literature findings and returned in Table 1. The LOD obtained in the present study is found reasonably lower than those reported previously as in Table 1 and hence could have potential implication in the detection of arsenic in the water bodies.

\subsection{Presence of Co-existing lons}

The influence of several co-existing ions was also studied in presence of $150 \mu \mathrm{g} / \mathrm{L}$ of each interfering ions. The As(III) concentration was taken $2.826 \mu \mathrm{g} / \mathrm{L}$ in $0.1 \mathrm{~mol} / \mathrm{L} \mathrm{KCl}$. The interfering ions were chosen as cadmium (II), chromium (VI), copper (II), manganese (II), phosphate and EDTA. The anodic stripping voltammetry curves are represented in Fig. S4. It is evident from the figure that no significant interference was occurred in presence of cadmium (II), chromium (VI), phosphate and EDTA. However, presence of copper (II) and manganese (II) caused to enhance the anodic peak signal and hence interfering the As(III) detection. Possibly the copper and manganese were oxidized at the same potential and hence, the anodic peak current was increased. The quantitative estimation of As(III) in presence of these co-existing ions are shown in Table S5. The $\mathrm{Au} / \mathrm{GO} /$ Leucine/Nafion electrode showed no interference in presence of $\mathrm{Zn}^{2+}, \mathrm{Pb}^{2+}, \mathrm{Hg}^{2+}$ and $\mathrm{Cd}^{2+}$ both having same concentration of $10 \mathrm{ppm}$ [1]. Similarly, the detection of As(III) in presence of $\mathrm{Pb}^{2+}, \mathrm{Co}^{2+}, \mathrm{Ni}^{2+}, \mathrm{Cd}^{2+}, \mathrm{Cu}^{2+}, \mathrm{Zn}^{2+}$ and $\mathrm{K}^{+}$is not affected significantly using the F-doped $\mathrm{CdO}$ electrode [18]. However, the presence of $\mathrm{Pb}^{2+}, \mathrm{Hg}^{2+}$ and $\mathrm{Cu}^{2+}$ caused a reduction of stripping current by 10, 30 and $65 \%$ for As(III) using the gold ultramicro electrode [42].

\subsection{Detection of As(III) in River Water Sample}

The intention of study was the implication of analytical method for the real matrix analysis of arsenic. The physico/chemical nature of river or ground water is found complex and it changes with

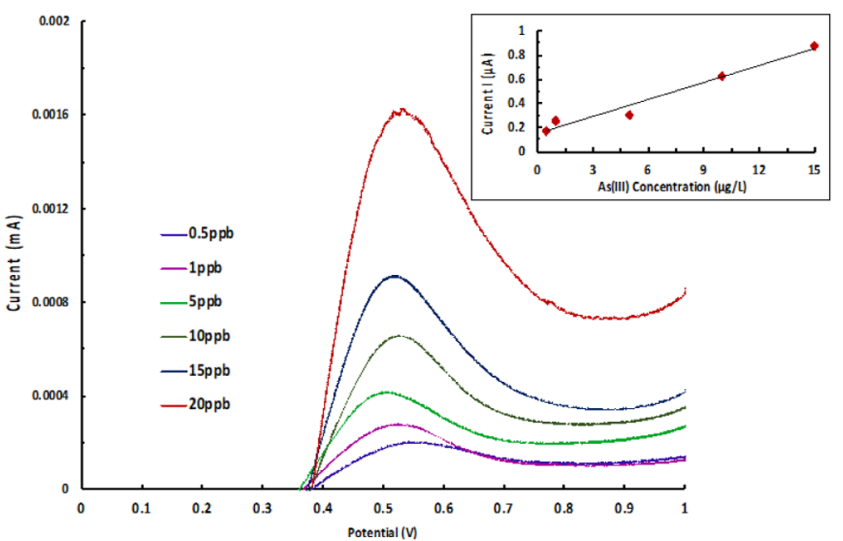

Fig. 7. Anodic stripping voltammetric studies for various concentrations of As(III) using Tlawng river water (Inset: Calibration line for the As(III) detection). Potential vs. $\mathrm{Ag} / \mathrm{AgCl}(0.1 \mathrm{~mol} / \mathrm{LKCl}$ and $\mathrm{pH} 2.0)$.

time and space. The water quality is greatly affected by the temperature, human intrusion, microorganism activities or even the nature of soil and rocks [15]. Therefore, a real matrix analysis enables us to find suitability, selectivity and feasibility of analytical method. Hence, the water was collected from the Tlawng River, Aizawl, India and employed without any filtration or purification. However, the river water sample was subjected for various physico-chemical analysis. The results are appended in Table S6. The results indicated that the water is free from several heavy metals however; it contained with $\mathrm{Ca}, \mathrm{Zn}$ and Fe. On the other hand, the high value of inorganic carbon and some NPOC is present. Further, the river water was spiked with varied concentrations of arsenic (III) at $\mathrm{pH} 2.0$ in 0.1 $\mathrm{mol} / \mathrm{L} \mathrm{KCl}$ background electrolyte. Further, the anodic stripping voltammetric analysis was conducted and results are shown in Fig. 7. It is evident that smooth curves are obtained and on increasing the concentration of As(III), the anodic peak current was increased gradually. Further, a regression line between the As(III) concentration and anodic peak current was plotted and shown in Fig. 7 (Inset). The regression line was obtained as $\mathrm{y}=0.0469 \mathrm{x}+$ $0.1523\left(R^{2}=0.9719\right)$. Reasonably a good linearity was obtained between the concentration and anodic peak current. Interesting to note that the RSD was always found less than $4 \%$. Further, an unknown solution of As(III) having known concentration 5.0 $\mu \mathrm{g} / \mathrm{L}$ at $\mathrm{pH} 2.0$ in $0.1 \mathrm{~mol} / \mathrm{L} \mathrm{KCl}$ was prepared in the same river water and subjected for the anodic striping analysis. Further, using the regression line, the As(III) concentration was estimated and found to be $4.9 \pm 0.02 \mu \mathrm{g} / \mathrm{L}$. This indicated that the recovery was more than 98\%. These results indicated that the devised method is useful in precise and efficient detection of arsenic at ultra-trace level. It provides fairly a good selectivity and sensitivity. The $\mathrm{SnO}_{2} / \mathrm{Nafion} / \mathrm{C}$ pencil electrode has shown fairly good applicability in qualitative and quantitative detection of As(III) from industrial waste water samples [19].

\section{Conclusions}


Novel silane grafted bentonite (nanocomposite) was synthesized using simple non-aqueous grafting method. The XRD data showed that silane was successfully grafted at the edges of bentonite and the $\mathbb{R}$ data enabled to show vibration peaks around wave numbers 3,039 and $2,880 \mathrm{~cm}^{-1}$ which is due to asymmetric and symmetric stretching of the $\mathrm{C}-\mathrm{CH}_{2}$ group of the alkyl chain and a scissoring oscillations of aliphatic organic chain was occurred around the wavenumber $1,489 \mathrm{~cm}^{-1}$. SEM morphological studies showed heterogeneous structure of nanocomposite and silanes molecules are visible on bentonite surface. Further, the nanocomposite material was employed in the electrochemical detection of As(III). The impedance spectroscopic data revealed for Nyquist plot and the equivalent circuit fitted to the Randles plot. The electroactive surface area was found to be $7.40 \times 10^{-3}, 1.52 \times 10^{-2}$ and $3.61 \times 10^{-2} \mathrm{~mm}^{2}$, respectively for the carbon paste, bentonite and nanocomposite electrodes. $\mathrm{pH}$ dependence studies indicated an enhanced electrochemical signal was obtained at $\mathrm{pH} 2.0$ with a minimum $\Delta \mathrm{E}$ values. The sensor studies enabled to low level detection of $\mathrm{As}(\mathrm{III})$ with a LOD $0.00360 \mu \mathrm{g} / \mathrm{L}$. The observed RSD were found less than $4 \%$. The presence of several cations and anions could affect the detection of As(III). However, a marked deviation was observed in presence of $\mathrm{Cu}(\mathrm{II})$ and $\mathrm{Mn}(\mathrm{II})$. The nanocomposite showed fairly good selectivity and sensitivity using the river water samples as spiked with As(III). The proposed method is a useful analytical method to be employed for the ultra-trace and, perhaps, on site detection of arsenic.

\section{Acknowledgments}

This research was supported by Basic Science Research Program through the National Research Foundation of Korea (NRF) funded by the Ministry of Education (NRF-2019R1I1A3A01062424).

\section{References}

1. Kumara S, Bhanjana G, Dilbaghi N, Kumar R, Umar A. Fabrication and characterization of highly sensitive and selectivearsenic sensor based on ultra-thin graphene oxide nanosheets. Sen. Actuat. B: Chem. 2016;227:29-34.

2. Liu Y, Huang Z, Xie Q, et al. Electrodeposition of electro reduced graphene oxide-Au nanoparticles composite film at glassy carbon electrode for anodic stripping voltammetric analysis of trace arsenic(III). Sens. Actuat. B: Chem. 2013;188:894-901.

3. Shukla S, Chaudhary S, Umar A, Chaudhary GR, Mehta SK. Tungsten oxide $\left(\mathrm{WO}_{3}\right)$ nanoparticles as scaffold for the fabrication of hydrazine chemical sensor. Sens. Actuat. B: Chem. 2014;196:231-237.

4. Fang H, Zhang J, Zhou S, et al. Submonolayer deposition on glassy carbon electrode for anodic stripping voltammetry: an ultra-sensitive method for antimony in tap water. Sens. Actuat. B: Chem. 2015;210:113-119.

5. Trachioti MG, Karantzalis AE, Hrbac J, Prodromidis MI. Low-cost screen-printed sensors on-demand: Instantly prepared sparked gold nanoparticles from eutectic $\mathrm{Au} / \mathrm{Si}$ alloy for the determination of arsenic at the sub-ppb level. Sens. Actuat.
B: Chem. 2019;281:273-280.

6. Shrivas K, Shankar R, Dewangan K. Gold nanoparticles as a localized surface plasmon resonance based chemical sensor for on-site colorimetric detection of arsenic in water samples. Sens. Actuat. B: Chem. 2015;220:1376-1383.

7. Song L, Mao K, Zhou X, Hu J. A novel biosensor based on Au@Ag core-nanoparticles for SERS detection of arsenic (III). Talanta. 2016;146:285-290.

8. Chakraborti D, Rahman MM, Ahamed S, Dutta RN, Pati S, Mukherjee SC. Arsenic groundwater contamination and its health effects in Patna district (capital of Bihar) in the middle Ganga plain, India. Chemosphere 2016;152:520-529.

9. B.K. Mandal, K.T. Suzuki. Arsenic round the world: A review. Talanta. 2002;58:201-235.

10. Zhou G, Pu H, Chang J, Sui X, Mao S, Chen J. Real-time electronic sensor based on black phosphorus/Au NPs/DTT hybrid structure: Application in arsenic detection. Sens. Actuat. B: Chem. 2018;257:214-219.

11. Mohan D, Pittman Jr CU. Arsenic removal from water/wastewater using adsorbents - A critical review. J. Hazard. Mater. 2007;142:1-53.

12. Liu ZG, Huang XJ. Voltammetric determination of inorganic arsenic. Trends Anal. Chem. 2014;60:25-35.

13. Sadrolhosseini AR, Naseri M, Kamari HM. Surface Plasmon resonance sensor for detecting of arsenic in aqueous solution using poly pyrrole-chitosan-cobalt ferrite nano particles composite layer. Opt. Commun. 2017;383:132-137.

14. Shrivas K, Shankar R, Dewangan K. Gold nanoparticles as a localized surface plasmon resonance based chemical sensor for on-site colorimetric detection of arsenic in water samples. Sens. Actuat. B: Chem. 2015;220:1376-1383.

15. Forzani ES, Foley K, Westerhoff P, Tao N. Detection of arsenic in groundwater using a surface plasmon resonance sensor. Sens. Actuat. B: Chem. 2007;123:82-88.

16. Kempahanumakkagari S, Deep A, Kim KH, Kailasa SK, Yoon HO. Nanomaterial-based electrochemical sensors for arsenic - A review. Biosensors Bioelectronics. 2017;95:106-116.

17. Guo Z, Yang M, Huang XJ. Recent developments in electrochemical determination of arsenic. Curr. Opinion Electrochem. 2017;3:130-136.

18. Gumpu MB, Mani GK, Nesakumar N, Kulandaisamy AJ, Babu KJ, Rayappan JBB. Electrocatalytic nanocauliflower structured fluorine doped $\mathrm{CdO}$ thin film as a potential arsenic sensor. Sens. Actuat. B: Chem. 2016;234:426-434.

19. Zhou C, Yang M, Li SS, et al. Electrochemically etched gold wire microelectrode for the determination of inorganic arsenic. Electrochim. Acta. 2017;231:238-246.

20. Ndlovu T, Mamba BB, Sampath S, Krause RW, Arotiba OA. Voltammetric detection of arsenic on a bismuth modified exfoliated graphite electrode. Electrochim. Acta. 2014;128:48-53.

21. Yang M, Guo Z, Li LN, et al. Electrochemical determination of arsenic(III) with ultra-high anti-interference performance using $\mathrm{Au}-\mathrm{Cu}$ bimetallic nanoparticles. Sens. Actuat. B: Chem. 2016;231:70-78.

22. Abeywardena SBY, Perera S, de Silva KMN, Tissera NP. A facile method to modify bentonite nanoclay with silane. Int. Nano Lett. 2017;7:237-241. 
23. Jović-Jovicíc $\mathrm{N}$, Milutinović-Nikolić A, Banković $\mathrm{P}$, et al. Synthesis, characterization and adsorptive properties of organo-bentonites. Acta Physica Polonica A. 2010;117:849-854.

24. Warchoł J,Misaelides P, Petrus R, Zamboulis D. Preparation and application of organo-modified zeolitic material in the removal of chromates and iodides. J. Hazard. Mat. B. 2006;137:1410-1416.

25. Madejová J, Komadel P. Baseline studies of the clay minerals society source clays. Clays Clay Miner. 2001;49:410-432.

26. Sacco A. Electrochemical impedance spectroscopy: Fundamentals and application in dye-sensitized solar cells. Renew. Sust. Energy Rev. 2017;79:814-829.

27. Lakhe MG, Rohom AB, Londhe PU, Bhand GR, Chaure NB. Study of photoelectrochemical conductivity mechanism and electrochemical impedance spectroscopy of bulk CuInTe $\mathrm{C}_{2}-$ Electrolyte interface. J. Surf. 2018;12:202-212.

28. Miao P, Wang BD, Han K, Tang YG. Electrochemical impedance spectroscopy study of proteolysis using unmodified gold nanoparticles. Electrochem. Commun. 2014;47:21-24.

29. Gu H, Yang Y, Chen F, et al. Electrochemical detection of arsenic contamination based on hybridization chain reaction and Rec Jf exonuclease-mediated amplification. Chem. Eng. J. 2018;353:305-310.

30. Lee SM, Zirlianngura, Anjudikkal J, Tiwari D. Electrochemical sensor for trace determination of cadmium(II) from aqueous solutions: Use of hybrid materials precursors to natural clays. Int. J. Environ. Anal. Chem. 2016;96:490-504.

31. Tiwari D, Zirlianngura, Lee SM. Fabrication of efficient and selective total arsenic sensor using the hybrid materials modified carbon paste electrodes. J. Electroanal. Chem. 2017;784:109-114.

32. Salinas-torres, Huerta F, Montilla F, Morallón E. Study on electroactive and electrocatalytic surfaces of single walled carbon nanotube-modified electrodes. Electrochim. Acta. 2011;56: 2464-2470.
33. Loučka T. The adsorption, oxidation and reduction of arsenious acid on gold and platinum electrodes. J. Electroanal. Chem. Interfacial Chem. 1973;47:103-108.

34. Xiao L, Wildgoose GG, Compton RG. Sensitive electrochemical detection of arsenic (III) using gold nanoparticle modified carbon nanotubes via anodic stripping voltammetry. Anal. Chim. Acta. 2008;620:44-49.

35. Lalhmunsiama, Tiwari D, Lee SM. Activated carbon and manganese coated activated carbon precursor to dead biomass in the remediation of arsenic contaminated water. Environ. Eng. Res. 2012;17:S41-S48.

36. Lee SM, Lalhmunsiama L, Thanhmingliana, Tiwari D. Porous hybrid materials in the remediation of water contaminated with As(III) and As(V). Chem. Eng. J. 2015;270:496-507.

37. Saha J, Roy AD, Dey D, Nath J, Bhattacharjee D, Hussain SA. Development of arsenic(v) sensor based on fluorescence resonance energy transfer. Sens. Actuat. B. 2017;241:1014-1023.

38. Ramesha GK, Sampath S. In-situ formation of graphene-lead oxide composite and its use in trace arsenic detection. Sens. Actuat. B: Chem. 2011;160:306-311.

39. Vandenhecke J, Waeles M, Riso RD, Corre PL. A stripping chrono-potentiometric (SCP) method with a gold film electrode for determining inorganic arsenic species in seawater. Anal. Bioanal. Chem. 2007;388:929-937.

40. Simm AO, Banks CE, Wilkins SJ, Karousos NG, Davis J, Compton RG. A comparison of different types of gold-carbon composite electrode for detection of arsenic (III). Anal. Bioanal. Chem. 2005;381:979-985.

41. Mafa JP, Mabuba N, Arotiba OA. An exfoliated graphite based electrochemical sensor for As(III) in water. Electroanalysis 2016;28:1462-1469.

42. Feeney R, Kounaves SP. On-site analysis of arsenic in groundwater using a microfabricated gold ultramicroelectrode array. Anal. Chem. 2000;72:2222-2228. 